\title{
"A.C.B. SERUM" OF PROF. BOGOMOLETZ IN THE TREATMENT OF RHEUMATISM
}

\section{FRANCIS BACH}

In the British Medical Journal of Aug. 14, 1943 (p. 203), Prof. Bogomoletz published an article in which he claimed that he had produced a serum the use of which caused considerable amelioration both of symptoms and of pathological tissue changes in " rheumatism." The Empire Rheumatism Council invited Prof. Bogomoletz to send some of this serum to this country in order that it might be tested upon patients here, and he readily acceded to this request. The Empire Rheumatism Council is now able to give an account of the trial of the serum.

\section{Theoretical Considerations}

Prof. Bogomoletz bases his treatment on his conception of the "physiological system of the connective tissue" described in his book Constitution and Mesenchyme. He stimulates the connective tissues by the use of a "cytotoxic serum." The principle underlying the treatment is to use the recipient's tissues as antigens. The serum is produced by the immunization of horses with the cells of the spleen and bone-marrow taken from a human corpse, preferably of a person who has died a sudden death. The antibodies thus produced are capable of "blocking" or "stimulating" the reticuloendothelial tissue of the recipient. The cellular elements of the reticulo-endothelial system produce various chemical substances which form the " haemato-parenchymal barrier," which Prof. Bogomoletz pictures as not only a barrier but a depot for various nutritive substances where the cells obtain the necessary "energetic and plastic resources." Upon the condition of this barrier depends the condition of the cells of the parenchyme, which he holds responsible for the general reactivity of the individual and his health and longevity. The substances which stimulate this system are present in the spleen and lymphatic nodes; they are "autocatalizators." For therapeutic purposes sera which give a complement fixation in a dilution of not less than 1 in 100 are found most suitable. The serum is injected at body temperature into the patient subcutaneously, the dose being $0.03-0 \cdot 10 \mathrm{c} . \mathrm{cm}$. diluted ten times with an isotonic solution of sodium chloride. Three injections are given at 2-3 day intervals; the last injection must be given not more than 10 days after the first. Prof. Bogomoletz claims that clinical experience has shown that this serum given in such doses has a strong stimulating $\overrightarrow{\vec{\omega}}$ effect on the cellular elements of the " physiological system of the connective tissue." In large doses the? serum has an inhibiting influence on these tissues.

\section{Physiological Action}

The mechanism of the stimulating action of ${ }_{z}$ A.C.B. serum is shown in a series of phenomena which occur within a few hours or days of its in-⿳⺈ jection. The first change to be noted usually $\vec{\varphi}$ follows the second injection. This is an increase in the permeability of the haemato-parenchymal barrier, a dilatation of the capillaries, and a significant relative lymphocytosis. The latter disappears within four hours and is replaced by a relative mono-o cytosis, and an increase in the number of adult seg- $\frac{0}{\circ}$ mented neutrophils which may remain for a few days. The amount of complement in the bloodo and the opsonic index are increased. The blood ${ }^{3}$ sedimentation rate when raised falls, and when low increases. There is a tendency for it to return to. normal. The purpose of the serum is to intensifye immunity. It acts not directly on micro-organisms or their toxins but on the "reactivity of the physio-3. logical system of the connective tissue," the con-i dition of which determines the destruction of patho-⿳亠丷厂 genic organisms and their toxins.

\section{Present Investigation}

It has been claimed that this is a valuable andr successful method for the treatment of "rheu+v matism." Many people suffering from a variety oN conditions diagnosed or labelled " rheumatism " of " arthritis" have asked their doctors about this new treatment. A careful review of the literature sent with the serum gives little indication as to the type of rheumatism, or the stage in the arthritic process at which the serum should be employed. It was thought advisable to take for study patients whos $\overrightarrow{8}$ ill-health had been carefully investigated from thథ clinical, laboratory, and radiographic aspects, an ${ }^{q}$ who could be classified under one or other of the recognized types of rheumatism.

Forty-eight patients in all have been investigate as in-patients 32, as out-patients 16 . They fall intothe following clinical groups, using the Royal College of Physicians' classification: 


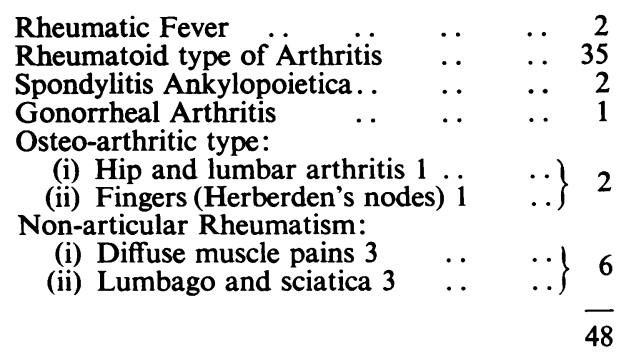

Clinical improvement was assessed on subjective features such as "feeling better," "less stiff," " eating and sleeping better," and on objective features such as a noticeable reduction in muscle spasm and joint swelling, a gain in weight, a return to normal of a raised temperature, and a fall in the sedimentation rate. In the main, when improvement occurred it was noted mainly in the subjective rather than the objective state. Clinical improvement was observed in fourteen: definite in 7; and slight in 7.

Of those who showed definite improvement, the type of disease was: rheumatoid arthritis in 3; rheumatic fever in 1; gonorrheal arthritis in 1; spondylitis ankylopoietica in 1; muscular rheumatism in 1 .

It is interesting to note that of the three rheumatoid arthritis who showed definite improvement, two were tired Lambeth women with advanced active rheumatoid arthritis who were admitted from an out-patients department in London into a Sector hospital outside London for a rest and were given the serum immediately. Pain was relieved, the joints became less swollen, and the blood sedimentation rate remained unchanged. They reremained in hospital a month. Two months later they had relapsed; one of them is again in hospital, her joints more swollen and painful than on her first admission. The third case was one of inactive rheumatoid arthritis in a young woman in whose symptomatology there was a very marked psychological factor. Two months after her discharge her symptoms had returned and were relieved by two injections of sterile water. The patient with muscular rheumatism, improving markedly, had a haemolytic streptococcal injection of the throat, with a raised sedimentation rate. The pain and swelling subsided and the streptococcus disappeared from the throat, and the sedimentation rate, which was high, returned to the upper normal limit. When re-examined two months later she was quite well, "felt better than she had for years," and the sedimentation rate was normal.

One of the two rheumatic fever cases improved considerably while under treatment, the joint swelling subsided, temperature and sedimentation rate returned to normal. It is hard to judge the extent to which the clinical picture and natural course of the disease in this case and in that of the acute gonorrheal arthritis were modified by the serum injections. The young man suffering from spondylitis ankylopoietica said that he felt better, but there was improvement neither in his chest expansion nor in the hip movements, and his sedimentation rate remained raised and unchanged.

Four of the patients with rheumatoid arthritis were referred by the Soviet Embassy. After the first course of treatment, three of these stated they were much better. At the end of the second course these three had unfortunately relapsed and said they had derived no benefit from the treatment. Two months later their condition was unchanged. They were patients in an advanced stage of rheumatoid arthritis who had come expecting a great deal from the new treatment.

The duration of each course of treatment was 7-10 days. The patients have now been under review for four to five months. All have been reexamined two months after their last injection. In 25 patients a diffuse and painful rash appeared at the site of the injection on the day after the second or third dose, and lasted for two or three days. In some cases the rash was quite mild; in others there was a circular patch, 3-4 inches in diameter, localized at the site of the injection. This was the only unpleasant reaction that was observed during the treatment.

The temperature of three patients was raised at the onset of treatment; at the end of a course of injections the temperature returned to normal in two of them. The first was a young man with rheumatic fever, temperature varying between 99 $100^{\circ} \mathrm{F}$. for a week before giving A.C.B. serum. The second was a young woman with arthralgia and a low-grade pyrexia in whom haemolytic streptococci were grown from the throat. The third was a middle-aged man suffering from rheumatoid arthritis in an advanced and active phase. The raised temperature was slightly less marked after the treatment.

In the rest of the series, the temperature was normal.

Blood Changes.-The blood sedimentation rate varied from $1 \mathrm{~mm}$. to $118 \mathrm{~mm}$. at the end of the first hour (Westergren). In some cases the sedimentation rate increased; in some it decreased; and in others it remained unchanged after one or two courses of injections. In those in whom clinical improvement was noted, it appeared to bear no relation to the height or change in the blood sedimentation rate.

Of the patients suffering from the rheumatoid type of arthritis who claimed definite improvement the blood sedimentation rate was within normal limits in one, out of three. In two out of the three it was raised, and was unchanged after the serum. In both the rheumatic fever cases the sedimentation rate was raised and after treatment it gradually returned to normal in the one; in the other it remained raised.

A differential blood count was done in some cases, but this showed no marked changes. For example, Mrs. P. was suffering from rheumatoid arthritis: 


\begin{tabular}{|c|c|c|c|c|c|c|c|c|c|}
\hline \multirow{2}{*}{ Date } & \multirow{2}{*}{$\begin{array}{c}\text { R.B.C. } \\
\text { Erythro- } \\
\text { cytes }\end{array}$} & \multirow{2}{*}{$\begin{array}{l}\text { Hb. } \\
\text { Haemoglobin }\end{array}$} & \multirow{2}{*}{ C.I. } & \multicolumn{5}{|c|}{ Leucocytes } & \multirow{2}{*}{$\begin{array}{l}\text { S.R. } \\
\text { Westergren }\end{array}$} \\
\hline & & & & Neutros. & Eosinos. & Basos. & Lymphos. & Monos. & \\
\hline 19.4 .44 & $5,040,000$ & $\begin{array}{l}12 \cdot 7 \text { g. per cent. ( } 92 \text { per cent. } \\
\text { acid haematin) }\end{array}$ & 0.92 & $16,750-9,390$ & 334 & 331 & 5,682 & 1,010 & 55 \\
\hline 28.4 .44 & $5,320,000$ & $\begin{array}{l}11 \cdot 32 \text { g. per cent. ( } 82 \text { per cent. } \\
\text { ac. Hn.) }\end{array}$ & $0 \cdot 77$ & $10,050-6,128$ & 100 & Nil. & 3,118 & 701 & 62 \\
\hline 15.5 .44 & $5,420,000$ & $\begin{array}{l}11.59 \text { g. per cent. ( } 82 \text { per cent. } \\
\text { ac. Hn.) }\end{array}$ & $0 \cdot 78$ & $13,450-10,220$ & Nil. & Nil. & 2,693 & 537 & 70 \\
\hline
\end{tabular}

\section{Comments}

This preliminary investigation does not support a claim that the A.C.B. serum can be considered as a "cure for rheumatism." That assessment of any method of treating the various disorders included in the term "rheumatism" is difficult has been shown by the results published of trials carried out in recent years in this country, the U.S.A., and on the Continent, with vaccines, gold preparations, vitamins, local injections, and so on. It is even more difficult to evaluate methods which are claimed to have a constitutional effect than those which merely offer to relieve pain or joint swelling. Although the rationale of gold treatment is not as yet clearly understood, many clinicians have claimed improvement in the general health of the rheumatic patient by its use, and this may well raise the hypothesis that by acting on the reticulo-endothelial system the resistance of the individual may be increased and the rheumatic process modified.

Prof. Bogomoletz and those Russian clinicians who have claimed success with the A.C.B. serum in the literature at our disposal neither define the type of " rheumatism" most amenable to benefit, nor give details of the range of dosage to be employed. It is possible, and even probable, that the type of case and the stage in the pathological process that has been used for this preliminary survey are not those कs which Prof. Bogomoletz would himself have chosen. $\vec{\circ}$ It is hoped that more detailed information will be $\overrightarrow{\vec{\omega}}$ given at some future date, so that a clinical and $\stackrel{\omega}{\omega}$ laboratory investigation on certain carefully selected $\cong$ groups of patients may be carried out, and results obtained which would justify the claims which have $\dot{\omega}$ been made for the A.C.B. serum. The results of $\mathrm{N}$ this preliminary investigation do not justify a o favourable verdict.

It gives me great pleasure to acknowledge the help and $\vec{z}$ encouragement which Lord Horder has given me through- 을 out this investigation and in the preparation of this $\frac{\rho}{\partial}$ Report.

The foregoing article was submitted to the Empire Rheumatism Council as a report on the tests which had been made. Mr. Paul Winterton, the Moscow correspondent of the News Chronicle received a copy of the report and approached Professor Bogolometz, who informed him that it was now his opinion that the serum is suitable for the cure of rheumatism only in the acute phase of the illness. Academician Nikolai Strozhesko, in whose clinic the action of the serum in rheumatism was studied, writes that the serum in stimulating doses produces the best effect with infectious diseases in the second (allergic) period of their course. In chronic rheumatism (chronic arthritis and endocarditis) the serum should not be used. 